\title{
How Do Engineering Scientists Think? Model-Based Simulation in Biomedical Engineering Research Laboratories
}

\author{
Nancy J. Nersessian \\ School of Interactive Computing, Georgia Institute of Technology
}

Received 10 July 2008; received in revised form 6 January 2009; accepted 26 March 2009

\begin{abstract}
Designing, building, and experimenting with physical simulation models are central problemsolving practices in the engineering sciences. Model-based simulation is an epistemic activity that includes exploration, generation and testing of hypotheses, explanation, and inference. This paper argues that to interpret and understand how these simulation models function in creating knowledge and technologies requires construing problem solving as accomplished by a researcher-artifact system. It draws on and further develops the framework of "distributed cognition" to interpret data collected in ethnographic and cognitive-historical studies of two biomedical engineering research laboratories, and articulates the notion of distributed model-based cognition to answer the question posed in the title.
\end{abstract}

Keywords: Model-based reasoning; Problem solving; Distributed cognition; Ethnography; Research laboratories; Mental modeling

[T]he component processes, which when assembled make the mosaic of scientific discovery, are not qualitatively distinct from the processes that have been observed in simpler problem-solving situations.

(Simon, Langley, \& Bradshaw, 1981, 2)

Just as you cannot do very much carpentry with your bare hands, there's not much thinking you can do with your bare mind.

(Dennett, 2000, 17)

Correspondence should be sent to Nancy J. Nersessian, School of Interactive Computing, Georgia Institute of Technology, Atlanta, GA 30332-0280. E-mail: nancyn@cc.gatech.edu 


\section{Introduction}

It has long been a central assumption of cognitive studies of science and technology that the cognitive resources scientists bring to bear in problem solving are not different in kind than those used in more ordinary instances, but lie along a continuum. Construing the reasoning and representational strategies scientists have developed as sophisticated, highly reflective outgrowths of ordinary reasoning and representational practices allows researchers in this area to both draw from and inform the study of the nature of cognition, in general. As with other areas of cognitive science there has been a move toward studying science in naturalistic settings (see, e.g., Alac \& Hutchins, 2004; Dunbar, 1995; Dunbar \& Blanchette, 2001; Goodwin, 1995; Hall, Stevens, \& Torralba, 2002; Nersessian, 2006; Nersessian, Kurz-Milcke, Newstetter, \& Davies, 2003; Trickett, Fu, Schunn, \& Trafton, 2000; Trickett $\&$ Trafton, 2007). One of the aims of the research I present here is to use insights gleaned from studying the problem-solving practices of engineering scientists to further an "environmental perspective" (Nersessian, 2005) on cognition. Our research aims at an integrated study of the embodied, artifact-using, and sociocultural dimensions of human cognition-one in which the environment does not simply scaffold cognition, but rather, in which aspects of the environment play integral roles in cognitive processes. Here I pose the question of "How do engineering scientists think?"

Engineering scientists are a breed of engineer-often interdisciplinary-whose research aims to make fundamental contributions to basic science as well as to create novel artifacts and technologies. Most often these researchers investigate real-world phenomena through simulation models - physical or computational. This research does not engage the in vivo phenomena under investigation directly; rather, they build in vitro models of selected features of in vivo phenomena and reason about the phenomena by means of manipulating the models. Thus, engineering science is a fundamentally analogical practice: experimentation is by means of models that are analog representations of entities and processes under investigation. Examining their use adds to extensive research on model use in philosophy of science and cognitive studies of science. That literature has largely examined the use of conceptual models in scientific research (see, e.g., Giere, 1988; Morgan \& Morrison, 1999; Nersessian, 1992a, 2008a). The philosophical work focuses mainly on issues pertaining to the relations between the models and the phenomena they represent, that is, the "realism" issue. As with my earlier work on "model-based reasoning," our research on the engineering sciences focuses on the nature of the intellectual work they accomplish through the use of models, now including physical and computational models as well.

The problem-solving practices of engineering scientists provide an excellent resource for advancing the agenda of environmental perspectives because their simulation technologies are simultaneously cognitive and cultural artifacts. Within the confines of this paper attention is directed primarily to one aspect - the function of physical models as cognitive artifacts in distributed cognitive processes-but in fact the sociocultural dimensions are always present if not attended to directly in this brief analysis. The epigraph quote from Daniel Dennett provides a pithy summary of a major premise of range of research under headings such as "distributed cognition," "the extended mind thesis," "situated 
cognition,' and "activity theory." The study presented here is framed, broadly, in terms of distributed cognition: cognitive phenomena such as problem solving are "distributed" (Hutchins, 1995) or "stretched"' (Lave, 1988) across a complex system comprising humans and artifacts. Within this framing, to understand how problem solving is achieved requires examining the generation, manipulation, and propagation of salient representations within the system; that is, examining how representational states flow across media and accomplish cognitive work. Early on in our investigation of two biomedical engineering research labs, our attention was directed toward highly salient representations, what they call 'devices,', which are the physical simulation models they design, construct, and manipulate in research.

The research presented here uses distributed cognition as an interpretive " framework' in the sense proposed by Ryan Tweney (Tweney, 1989): “A framework is an attempt to reconstruct a model of the world that meets criteria other than testability [required for theories] as such. An adequate framework is one that is consistent with the details of the real-world process, is interestingly related to our theories of the world, and reduces the complexity of the real-world process in a way that permits anchoring the framework to the data' (p. 344). I would add to this that framework analyses have the potential to lead to new hypotheses that can be explored and tested in experimental research (see also Dunbar, 1995). Further, "distributed cognition"' is itself a notion under development and one objective of this work is to further articulate it.

By now, several real-world-and experimental-phenomena have been analyzed and interpreted by means of the distributed cognition framework. In their discussion of it in the context of human-computer interaction, Hollan et al. (Hollan, Hutchins, \& Kirsch, 2000) listed three possible kinds of distributed cognitive processes arising from "observation of human activity 'in the wild",':

1. Cognitive processes may be distributed across the members of a social group.

2. Cognitive processes may involve coordination between internal and external (material or environmental) structure.

3. Processes may be distributed through time in such a way that the products of earlier events can transform the nature of later events (p. 176).

The problem-solving activities of the research laboratories we have studied exhibit all three kinds, though here I focus largely on the latter two. What is novel about these domains is that all aspects of the system — human and technological—are simultaneously undergoing interrelated changes (Nersessian et al., 2003). Although there are loci of stability in these research communities, problem-solving processes are often of long duration and involve designing, building, and redesigning the technology. Furthermore, all researchers are learners. As we have found, the researchers and their technologies have intersecting developmental trajectories.

In what follows, I first characterize the environments and our methods of analysis. I then develop a system level interpretation of the research activities we call interlocking models and its correlated notion, model-based cognition, to explicate how 
problem solving is achieved by a distributed inferential system comprising researcher(s) and $\operatorname{artifact}(\mathrm{s})$.

\section{Methods of data collection and analysis}

\subsection{Cognitive-historical ethnography}

Our own interdisciplinary research group comprises $\mathrm{PhD}$-level researchers with expertise in ethnography, qualitative methods, linguistics, psychology, philosophy and history of science, cognitive science, and learning sciences. Student researchers (graduate and undergraduate) have come from programs in cognitive science, intelligent systems, and human-centered computing. All members of the team received apprenticeship training in ethnography, qualitative methods, and cognitive-historical analysis.

Following researchers in distributed and situated cognition who have adapted ethnographic methods from anthropology to study cognitive processes in naturally situated practices (Goodwin, 1995; Hutchins, 1995; Lave, 1988), we conducted "cognitive ethnographies" (Hutchins, 1995) of the research laboratories. The ethnographic part of the study (observations and interviews) has sought to uncover the activities, tools, and meaningmaking that support research as situated in the ongoing practices of the community. Several members of the group became participant observers of the day-to-day practices in each lab. We took field notes on our observations, audiotaped interviews, and video- and audiotaped research meetings (full transcriptions are completed for 148 interviews and 40 research meetings). We focused our attention on the custom-built simulation models (devices) as these appeared to function as "hubs" around which cognitive, social, and cultural practices centered. Because our focus was on the day-to-day activities surrounding the devices, the research meetings (monthly or less for Lab A and biweekly for Lab D), though useful, assumed less importance than they have in other studies of cognitive practices in laboratories (see, esp., Dunbar, 1995). We needed more to elicit from researchers their understanding and perceived relations to these artifacts, and to see how they functioned within the life of the labs-aspects that are better addressed through interviewing and extensive field observations. The historical dimension of research in these laboratories, especially with respect to the simulation devices, required that we bring together interpretive methods akin to those used in cognitive-historical analysis (Nersessian, 1995) with the qualitative methods of cognitive ethnography. In this use, cognitive-historical analysis examines historical records with the objective of understanding cognition, rather than constructing an historical account per se. For this dimension of our study, data collection included publications, grant proposals, dissertation proposals, powerpoint presentations, laboratory notebooks, e-mails, materials related to technological artifacts, and interviews on lab history.

As a group we estimate conducting over $800 \mathrm{hr}$ of field observations. Although we were allowed to video research meetings, it proved unfeasible to video research in the laboratories. The kinds of observations we were after were not amenable to requesting to be notified so that we could film when " $\mathrm{X}$ " was happening. In Lab D, one researcher did consent to 
letting us video her at a distance during research, but she found it a distraction and uncomfortable. She kept asking that we "move farther away" until it was no longer useful. Furthermore, research took place all hours of the day (one of our researchers camped out evenings in Lab D because in its early days we could not predict when the members would be there and some only came to the lab in the evening hours). Mounting overhead cameras running continually or providing head cameras for the researchers to wear might have been useful, but both were prohibitively expensive and posed serious human subjects' issues.

\subsection{Field sites: Two biomedical engineering research laboratories}

We have conducted a 5-year investigation of two university research laboratories in the area of biomedical engineering. Specifically, we began in the first year with a tissue engineering laboratory and added a neural engineering laboratory in the second year. Intensive data collection was conducted in each laboratory for 2 years with follow-up of the participants, their research, and questions pertaining to our research for an additional 2 years. ${ }^{1}$ Analysis is ongoing.

We selected these sites in accord with the multiple aims of our research. A central aim is to examine cognitive practices in interdisciplinary fields and the challenges these pose for learning. Salient features of the sites are as follows:

1. They are rich locales for investigating the interplay of cognition and culture in creative scientific practices.

2. They are significant sites of learning in science and engineering fields.

3. They are interdisciplinary communities where concepts, methods, discourses, artifacts, and so forth, from different disciplines interact.

Lab A is a tissue engineering laboratory. During our study, the main members included a director, one laboratory manager, one postdoctoral researcher, seven $\mathrm{PhD}$ graduate students (three graduated while we were there; the other four, after we concluded formal collection), two MS graduate students, four long-term undergraduates (two semesters or more). Additional undergraduates from around the country participated in summer internships and international graduate students and postdocs visited for short periods. The laboratory director ("A13") was a senior, highly renowned pioneer in the field of biomedical engineering. All of the researchers came from engineering backgrounds, mainly mechanical or chemical engineering, and some were currently students in a biomedical engineering program. Some had spent time in industry prior to joining the lab. The lab manager had an MS in biochemistry. Researchers frequently consulted with a histologist located in the building and traveled to other institutions for various purposes, including to collect animal cells and to run gene microarray analyses. The tissue engineering laboratory, as an institution, had been in existence nearly 20 years when we entered.

Lab A's overarching research problems are to understand mechanical dimensions of cell biology, such as gene expression in endothelial cells, and to engineer living substitute blood vessels for implantation in the human cardiovascular system. The dual objectives of this lab 
explicate further the notion of an engineering scientist as having both traditional engineering and scientific research goals. Examples of intermediate problems that contributed to the daily work during our investigation included designing and building living tissue_- "constructs" - that mimic properties of natural vessels; creating endothelial cells (highly immune-sensitive) from adult stem cells and progenitor cells; designing and building environments for mechanically conditioning constructs; and designing means for testing their mechanical strength.

Lab D is a neural engineering laboratory. During our study the main members included a director, one laboratory manager, one postdoctoral researcher, four $\mathrm{PhD}$ graduate students in residence (one left after 2 years, three graduated after we concluded formal collection), one $\mathrm{PhD}$ student at another institution who periodically visited and was available via video link, one MS student, six long-term undergraduates, and one volunteer for nearly 2 years, not pursing a degree (with a BS), who helped out with breeding mice. When we began, the laboratory director ("D6") was a new tenure-track assistant professor, fresh from a 7-year postdoc in a biophysics laboratory that develops techniques and technologies for studying cultures of neurons. He already had achieved some recognition as a pioneer. His background was in chemistry and biochemistry, with his engineering experience largely self-taught, though highly sophisticated. The backgrounds of the researchers in Lab D were more diverse than Lab A and included mechanical engineering, electrical engineering, physics, life sciences, chemistry, microbiology, and some were currently students in a biomedical engineering program. As an institution, the neural engineering laboratory was in existence for a few months and still very much in the process of forming when we entered.

Lab D's overarching research problems are to understand the mechanisms through which neurons learn in the brain and, potentially, to use this knowledge to develop aids for neurological deficits and "to make people smarter'" (PI). Examples of intermediate problems that contributed to the daily work included developing ways to culture, stimulate, control, record, and image neuron arrays; designing and constructing feedback environments (robotic and simulated) in which the "dish" of cultured neurons could learn; and using electro-physiology and optical imaging to study "plasticity." Here, again, the researchers have dual scientific and engineering agendas.

\subsection{Research questions}

Several questions pertaining to cognitive and learning practices in these labs served to frame our investigation. The most significant for this paper were as follows:

1. What are the cognitive practices in research in these areas?

2. What are the investigative practices through which research problems are addressed?

3. What are the interactional practices within the laboratory culture that facilitate and sustain learning and research?

As a way of capturing relations among cognitive and cultural facets of the system, we formulated an analytical scheme comprising cognitive, investigative, and interactive practices. 
Cognitive practices give rise to and interact with investigative practices, which in turn are enacted through interactional practices, which support and sustain both. In this framework, cognitive practices include the problem formulation, reasoning, and problem-solving approaches that drive the work in the lab. Deriving from these, the investigative dimension comprises the nature of the lab members' daily work as they strive to develop understanding, techniques, and technologies. The interactional dimension comprises the lab culture and the social configurations that account for the kinds and nature of relationships formed in the lab and how these are sustained.

Our research findings are rich, and the account and interpretations presented in this paper are largely restricted to those pertaining to a central cognitive practice of crossing the in vivo-in vitro divide and the associated investigative practice of designing, building, and experimenting with simulation models and interactional practice of "cognitive partnering." The simulation models, called devices within these labs, provide the means through which researchers screen, control, and investigate the in vivo world via creating parallel in vitro worlds. Cognitive partnering denotes the idea that the research involves building relationships both with other researchers and with devices.

\subsection{Coding methods}

Broadly consistent with the aims of grounded theory, we have been approaching interpretive coding analytically and inductively (Glaser \& Strauss, 1967; Strauss \& Corbin, 1998) enabling core categories (and eventually "theory",2) to emerge from the data and remain grounded in it, while being guided by our initial research questions. Coding began with weekly collaborative meetings by two PhD-level psychologists with qualitative methods expertise. A small sample of interviews were analyzed progressively line-by-line from beginning to end, with the aim of providing an initial description for most if not all passages in the interview. A description and code were recorded only when both researchers were in full agreement about its fit and relevance to the passage and, initially, there was no attempt to minimize the number of coding categories. Two main approaches to developing codes proved most productive. One was consistent with classic grounded coding approaches that emphasize the emergence of themes and codes from described units of text. The second approach arose in closer connection with ongoing ethnographic field observations in the labs. Initial codes were presented in our biweekly research group meetings (all had read the transcripts in advance) and codes were discussed until there was agreement. Descriptions and codes were revisited throughout the process in keeping with new discussion on the text, as well as new observations in the laboratories. Codes were then analyzed for conceptual similarities, overlap, and distinction, and were grouped together under superordinate headings, and so forth until no further reductions could be made.

Once codes were established several student researchers were trained on these, with special emphasis on the codes that had been collected under the category "model-based cognition" and a larger number of transcripts were "high level' coded for instances of these. Again at least two researchers looked at the same transcripts and resolved any conflicting interpretations through discussion. Of the fully transcribed interviews $18 \%$ are 
coded. In this process, 79 categories emerged that transferred across the two labs. Of these 27 were particularly robust, and in all 11 superordinate categories were constructed. The 11 superordinate categories demonstrate the range of emergent codes: agency, analogy, history, identity, limitations, model-based cognition, norms, pragmatic, problem formulation, seeking coherence, and visualization. One exemplar from the superordinate categories is "model-based cognition." In the coded transcripts, 389 instances fall under this superordinate category. ${ }^{3}$ Fig. 1 provides subcategories and sample instances.

By "'model-based,' we mean that the representation was organized to reflect structural, functional, or behavioral aspects of the phenomena. Thus, we infer that these researchers understand, explain, and reason with "mental models," as will be discussed in Section 4.

To ensure the "trustworthiness" (Lincoln \& Guba, 1985) of our interpretations, we followed Eisner's (2003) three principles: structural corroboration, referential adequacy, and consensual validation. Structural corroboration requires that a sufficient number of data points converge on a conclusion to support the interpretation arrived at. This principle calls for triangulation among different data types, in our case, interviews, field notes, lab meetings, and documents. Referential adequacy addresses the richness of the description and interpretation and whether it aligns with member understanding of the same phenomena. It is important to be able to clearly and succinctly explain the properties of each coding category for the sake of transparency. In our early coding phases we presented interpretations to lab members to check for alignment. And finally consensual validation refers to the level of inter-rater agreement that can be reached among two or more team members using the coding schemes. Failure to achieve such validation means that the coding scheme is not well corroborated in the data or adequately described. Our consensual validation procedures were as discussed above.

\section{SUPER-ORDINATE CATEGORY \\ Model-based cognition}

\section{CATEGORIES}

Model-based understanding

Referencing, demonstrating, explaining, giving evidence of comprehension in terms of an organized representation

Model-based reasoning

Evidence of reasoning through model construction and manipulation; marked by inferences ("if..then," "thus," "it seems like," "maybe," "I suspect," "so," etc.)

\section{Model-based explanation}

Using models to communicate, to convey understanding

\begin{abstract}
"So, we've come up with this flow loop as a way to impose a very well-defined shear stress across a very large population of cells such that their aggregate response will be due to that well-defined shear stress."
\end{abstract}

\footnotetext{
"They're [neurons] feeling and touching and probing around their environment until they find the right partners to form a network with. And I suspect a lot of the decision has to do with the activity going on in the dish as well. So, perhaps if they get a certain signal, electrical signals at the same time they make contact, they may decided to form a permanent connection. And the reason I suspect this is because there is very good evidence in animals ....."

"If you look at a blood vessel, from this scale it looks like a tube. If you were a millimeter tall, then they look pretty flat. So we use that [flat construct] as our approximation of the tubular surface."
}

Fig. 1. Model-based cognition examples. 


\section{Laboratory practices}

In this section, I develop examples of central cognitive, investigative, and interactional practices in each laboratory.

\subsection{Cognitive practice: Traversing the in vivo-in vitro divide}

Research in both of the laboratories we have studied is driven by the need to solve complex, interdisciplinary problems. The central cognitive practice is traversing the in vivo-in vitro divide. Research in biomedical engineering confronts the problem that it is impractical or unethical to carry out experiments directly on animals or human subjects. Thus, ways must be devised to emulate selected aspects of in vivo phenomena to a degree of accuracy sufficient to warrant transfer of selected aspects of simulation outcomes to the in vivo phenomena. As a result, the central investigative practice common to both labs is to design, build, and experiment with in vitro simulation models that aim to parallel selected features of in vivo systems. ${ }^{4}$ The researchers refer to their physical models as "devices," which are usually signature artifacts of that laboratory or of a small group of laboratories in the research area. Experimentation with devices requires configurations in which biological and engineering components are brought together in an investigation, which researchers refer to as a "model system." As one respondent stated: "when everything comes together I would call it a 'model system' [...] I think you would be very safe to use that [notion] as the integrated nature, the biological aspect coming together with an engineering aspect, so it's a multifaceted modeling system. I think that's a very good terminology to describe that.' Many interactive practices, for instance, mentoring newcomers, develop around the devices. In particular, as learners mature into full-fledged researchers, they come to see the simulation models as partners and active participants in their research. We call this interactional practice, cognitive partnering.

\subsection{Investigative practice: Experimentation through simulative modeling}

The need to traverse the in vivo-in vitro divide gives rise to the investigative practice of experimentation through simulative modeling. In the labs we studied, physical simulation was the primary means of investigation, though Lab D made some use of computational simulation. As the primary objective of this paper is to discuss our cognitive interpretations stemming from this research, I offer only a brief example of the modeling practices with devices in each lab.

\subsubsection{Lab A: The flow loop and construct}

Research in Lab A stems from the insight its director had in the early 1970s: "characteristics of blood flow [mechanical forces] actually were influencing the biology of the wall of a blood vessel. And even more than that....the way a blood vessel is designed is-it has an inner lining called the endothelium. It's a monolayer....it's the cell layer in direct contact with flowing blood. So it made sense to me that, if there was this influence of flow on the 
underlying biology of the vessel wall, that somehow that cell type had to be involved." (Note the "design"' perspective on biology of a mechanical engineer!) The device that is now the central focus of research in Lab A is the cell-seeded vascular graft ("construct") that is a living, tissue-engineered representation of a blood vessel wall (Fig. 2A). The nature of the representation changes along various dimensions depending on the constraints of the experiment in which it will be used. For instance, it can be seeded with smooth muscle cells and endothelial cells, or simply the latter (derived from a variety of animals) and the components of the collagen scaffolding can vary. Its design is based on what is currently understood of biological environment of endothelial cells in cell and vascular biology, the kinds of materials available, and bio-engineering techniques thus far developed. Their ongoing research serves to advance all of these aspects.

Once built, a specific construct representation can be manipulated by various means. One form of manipulation is by the flow channel device ("flow loop"), an engineered representation of the in vivo force of blood flow over the lumen; that is, it is a model of hemodynamics (Fig. 2B). The flow loop design is based on the fluid mechanics of a long channel with a rectangular cross-section. In exposing the endothelial cells lining the construct to shear stresses, this manipulation "conditions" or "exercises" the cells and can be the locus of an experimental process itself (e.g., relating to cell morphology or gene expression), or just one step in a multimodel process. To determine the results of a flow loop manipulation, the conditioned construct is removed and examined with various instruments, such as the conditioned construct with a confocal microscope, an instrument that generates images for many color channels, at multiple locations, magnifications, and gains.

\subsubsection{Lab D: The MEA dish and embodiments}

The central simulation device in Lab D is the multielectrode neuron array, locally referred to as "the dish." The research in this laboratory stems from the director's desire to

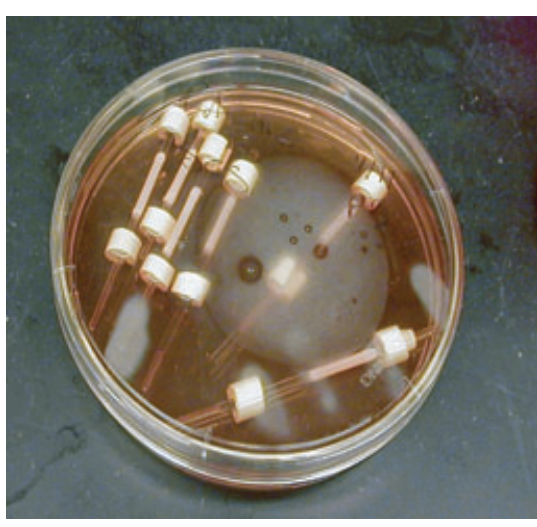

(A)

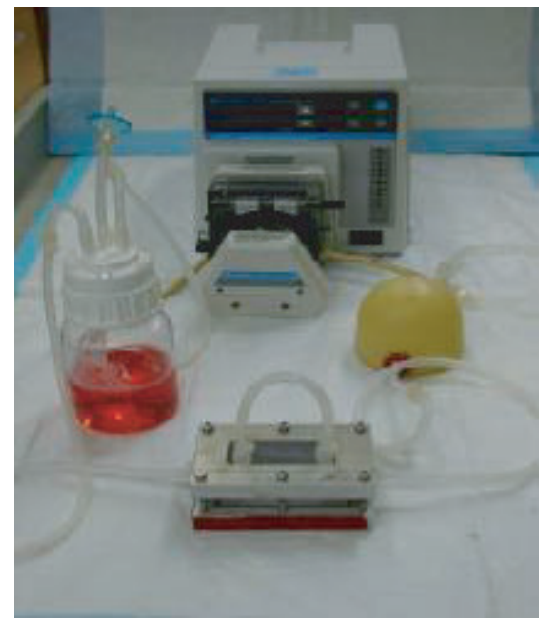

(B)

Fig. 2. Photographs of tubular constructs on mandrills in a culture (A) and a flow loop set-up (B). 
understand the nature of network activity of the brain. "There are a lot of people out there doing very detailed modeling of single neurons.... but I'm much more interested in what happens when you take a bunch of cells and have them interact with one another, what sort of emergent properties pop up.... that's part of our job to find out which of the details of the biology are important in these sorts of network properties and network phenomena, and which are sort of incidental.' He spent his postdoc years developing ways of growing (and keeping alive for years), recording, and imaging live in vitro networks of neurons to study how they learn, and these now form the basis for research in Lab D.

The very construction of the "dish" of cultured neurons interlocks concepts, methods, and materials from biology, chemistry, and electrical engineering. The neurons are plated on a multielectrode array (MEA), which is a small, glass, Petri-style dish with an $8 \times 8$ grid of microelectrodes embedded in the bottom (Fig. 3A). The electrodes poke into the neurons giving researchers the capacity for recording and injecting electrical activity in the network (Fig. 3B). The living cells (around 40K) are neurons and glia harvested from a rat's cortex, dissociated, and cultured in the Petri dish, bathed in a medium of biological chemicals that provide food. Finally, a Teflon film is stretched over the dish and held in place by another Teflon 'O' '-shaped piece. Teflon is used because it is nontoxic and allows oxygen and carbon dioxide to pass through so the cells can breathe, while at the same time keeping out bacteria and fungi. For recording, stimulating, and imaging purposes, the dish needs to be enclosed in a sterile environmental chamber.

The MEA dish is a generic representation of cortical processing behavior and function, but "it's a simplified model... it's not how it is in the brain, but I still think that the model would answer some basic questions." Part of the research in Lab D is determining more specifically the nature of the modeling representation, which includes learning to interpret, control, and mathematically represent the dish's behavior under various conditions of stimulation.

Although the details cannot be specified here, some of the most important model system simulations it participates in are closed loop configurations or "embodiments," which

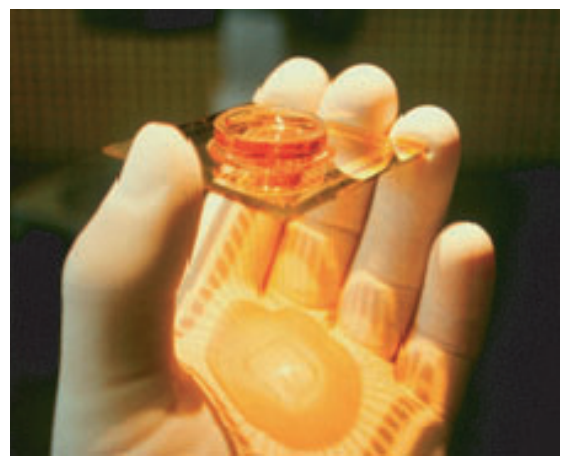

(A)

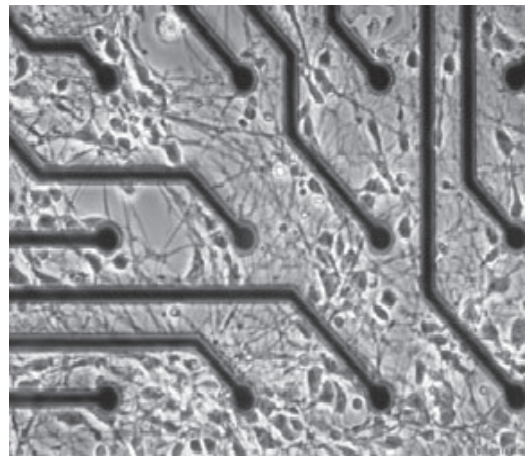

(B)

Fig. 3. Photograph of the MEA (A) and the neuron dish (B). 
represent the in vivo embodiment of the brain. One involves its connection to a computationally simulated animal and world in which it "behaves" — called an "animat." The other involves connection with various robotic devices designed to mimic motor activity in the world-called a "hybrot." These model systems bring the domains of computational modeling and mechanical engineering, respectively, into the interdisciplinary mix.

The arrows in Fig. 4 represent the flow of representations (solid boxes) as the information they provide is generated, manipulated, and propagated within the artifact model system.

\subsection{Interactional practice: Cognitive partnering}

We use the notion of cognitive partnering to characterize the special relations that develop among researchers and between them and simulation devices (as opposed to with other important artifacts such as the pipette or the confocal microscope) in the course of learning in the lab (Nersessian et al., 2003; Osbeck \& Nersessian, 2006). What it means for learners to form cognitive partnerships with other researchers is fairly straightforward. However, we developed the notion in the first instance to capture the significant shift in the way learners think and talk about, and interact with their devices_-and only these-as they progress in their research. Significantly, the language used to discuss the devices shifts from that of the newcomer who discusses "that thing over there with hooks and pulleys" to that of the advancing researcher who increasingly uses anthropomorphic language as she becomes more expert. Although much of it concerns cells, which are living entities, significantly, this language use extends to nonliving parts of model systems as well. Some examples of both are as follows:

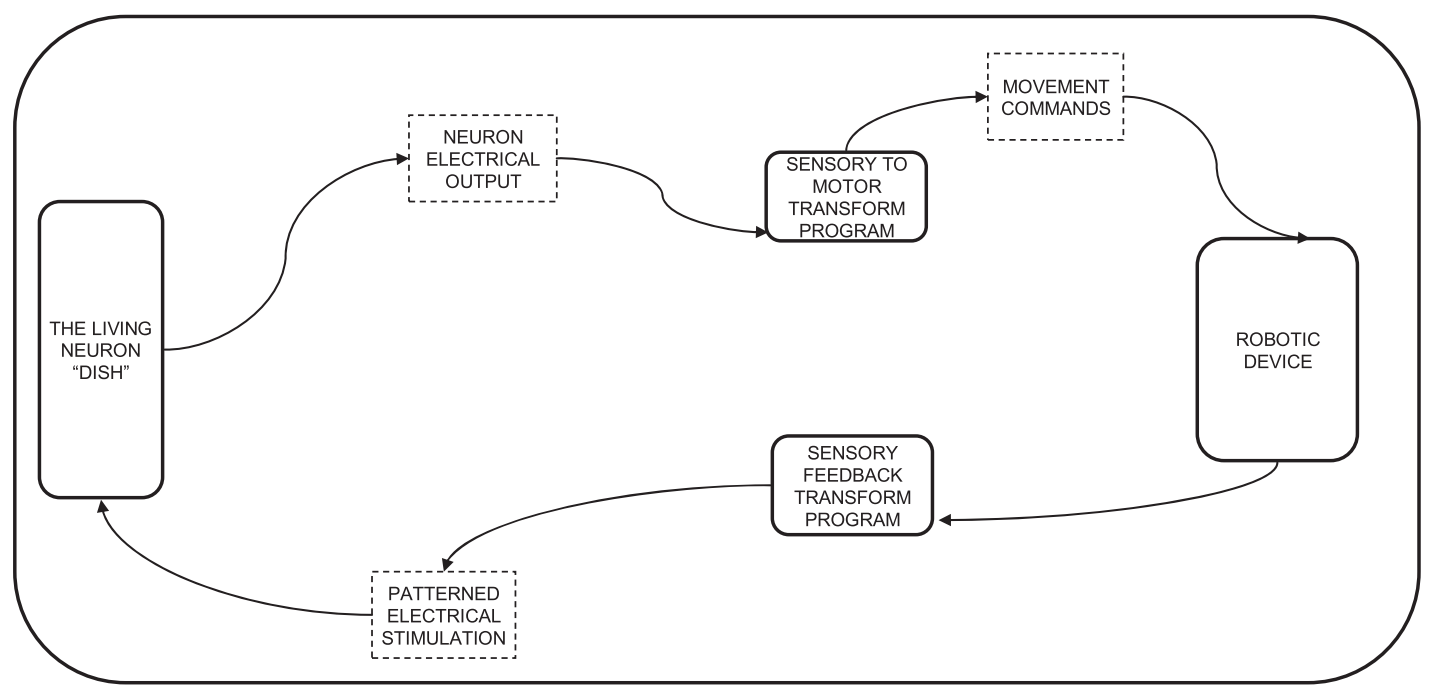

Fig. 4. Hybrot model system (partial). 
1. I'm strengthening that particular pathway so that the network would prefer to always excite these two cells in a certain way after my modifying input. (Dish model system-Lab D)

2. The cells once they are in the construct will reorganize it and secrete a new matrix and kind of remodel the matrix into what they think is most appropriate. (Construct model-Lab A)

3. [The board] sees voltages in different ways. (Bioreactor model—Lab A)

4. Yeah, seven parameters it has to look at in order to decide what's a burst. (Burst detector software in dish model system-Lab D)

We construe such anthropomorphizing as signaling the researcher's attribution of agency to the artifact. As the researcher matures, the simulation device comes to be conceived as a "partner" in research. In one sense, cognitive partnering marks coming to understand the research through the lens of what the device affords and constrains. But it goes beyond this to conceptualizing the devices as possessing quasi-independence-as distinct from and interacting with the researcher. In the course of experimenting, the artifact reacts and interacts often in undesired or unexpected ways, which leads the researcher to come to treat the device as an active participant in the investigative process. ${ }^{5}$ Finally, this language signals, too, that there is an affective dimension of research, as there is in forming relationships generally. This is evidenced, for instance, by a researcher in Lab A telling a newcomer to "think of them [cells] as pets" and by the frustration of a researcher in Lab D with the behavior of her device: "Pfft—you keep them [the dish neurons] happy by feeding them, by taking care of them, hopefully stimulating them [in a motherly and condescending voice], and telling them to do something! I don't know what to do to make them happy. I don't know—make them happy!' If the MEA dish is not happy, neither is the researcher.

\subsection{Discussion}

These laboratories are rich sites that provide numerous findings about cognition and learning. Given that the objective of our research has been to discover practices that might be in common use in the field of biomedical engineering we focused on those coding categories and interpretations that transferred robustly across the labs. Each laboratory provided us with a systemic perspective of their research. Fig. 5 provides a self-mapping of the research space for each laboratory. Fig. 5A was drawn by the Lab A director in response to our request that he "draw a picture" of the research in his lab. He mapped not only the problems ("major barriers") but also the technologies (at the bottom), the relations of researchers to both of these and to one another in that space. The content of Fig. 5B was constructed by the entire Lab D research group in a meeting we observed which they organized specifically to "map the research," that is, to consider the nature of the problems, the range of resources, and the potential range of contributions for their research. The lab director then created this representation from what was written on the white boards, and video and audio capture of the discussion. Here too, problems and technologies delimit a finite, though significantly unconstrained, research space. In this case, he did not draw the relational 
Mapping the research

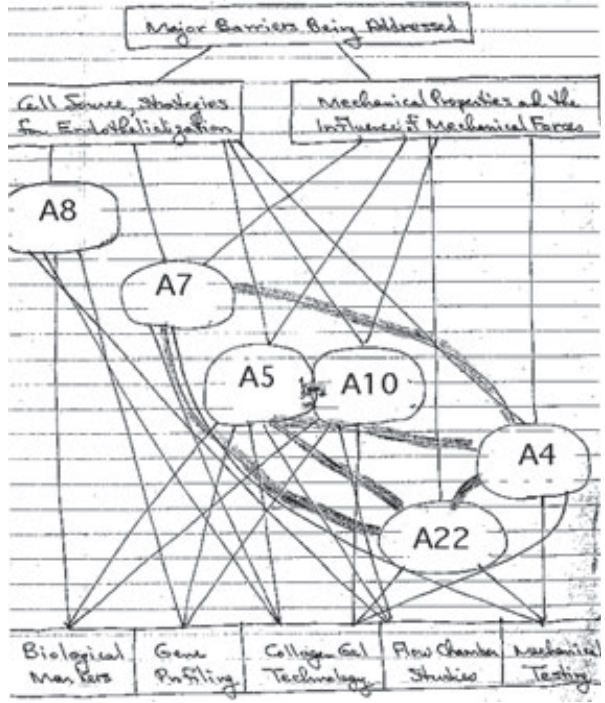

(A) Lab A

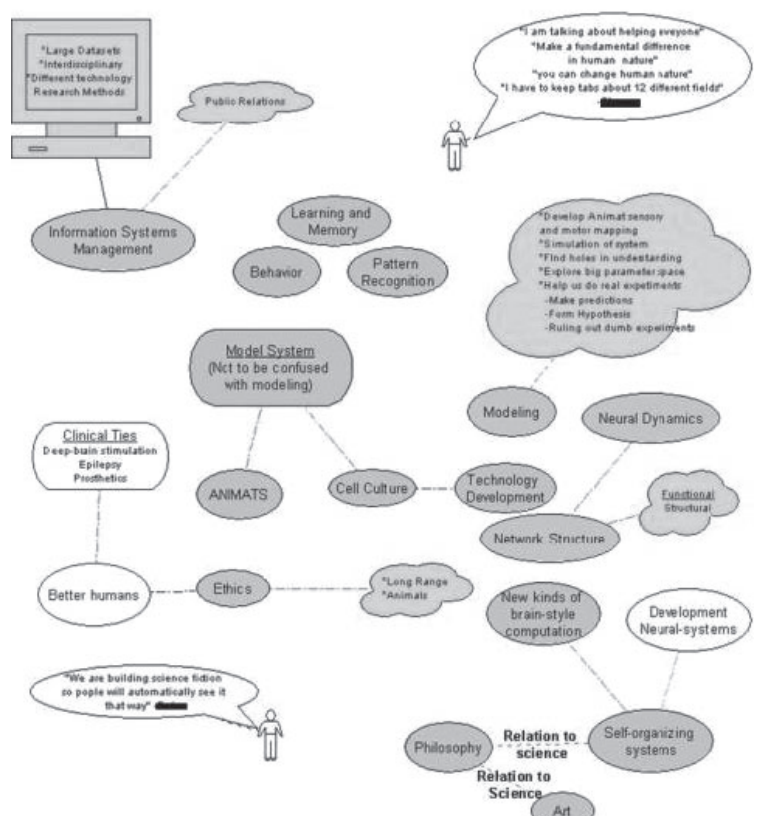

(B) Lab D

Fig. 5. Laboratory research spaces.

information concerning the researchers, but it did form part of their discussion. So the fuller mapping comprises the diagram and the video and audio capture.

Each map begins to articulate a research space distributed across problems, methods, technologies, and members, as well as connecting the lab to resources and communities external to it. For example, for Lab A "gene profiling" requires using technology at a nearby medical school; for Lab D "clinical ties" relate to other research communities. These lab mappings reinforce our observations that the research activities in both labs center on the devices. The devices, as hubs, connect researchers, problems, and technologies. They are the primary sites of inquiry, innovation, and learning.

The investigative practice of using in vitro simulation is deeply implicated in these mappings. In order to address the "barrier" of "mechanical properties" of endothelial cells in vivo, for instance, one needs to design and use flow chambers and collagen gel constructs. One needs to build "science fiction" (as the Lab D member utters) to achieve science fact. The devices, as models, are designed to represent what researchers deem to be salient properties and behaviors of biological systems. But the devices are also systems themselves, with engineering and material constraints that often impose simplifications and idealizations unrelated to the biological systems they model.

Devices are hybrid objects reflecting the laboratories as bio-engineering environments and reflected in the characteristics of the researcher-students who are part of a program 
aimed explicitly at producing interdisciplinary, integrative thinkers in biomedical engineering. Given the hybrid nature of the simulation models, a major learning challenge for these researchers is to develop selective, integrated understandings of biological concepts, methods, and materials and engineering concepts, methods, and materials. By "selective," I mean that a researcher-learner needs to integrate, in thinking and experimenting, only those dimensions of biology and engineering relevant to their research goals and problems. For example, in Lab A, researchers need to develop an integrated understanding of the endothelial cell in terms of the stresses of fluid dynamics of blood flow in an artery. In Lab D the notion of plasticity, a biological property, needs to be understood in terms of quantitative measures based on recorded spikes of electrical activity of the neuronal network.

Further, in designing and conducting experiments with devices, researchers need to understand what engineering constraints they possess deriving from their design and construction, and what limitations these impose on the simulation and subsequent interpretation and inferences. That is, the device needs to be understood both as device qua in vitro model and device qua engineered model. Thus, whatever inferences researchers make about the in vivo phenomena are conditioned on an understanding of the device both as a model of the phenomena and as an engineered system.

Building activities centered on devices are pervasive in both laboratories and these serve several functions within the research community. Devices connect the cognitive practice of in vitro simulation with social practices; for instance, much initial mentoring and learning of laboratory ethos takes place in the context of cell culturing-something all newcomers must master. For newcomers, building cell cultures, constructs, and MEA dishes serves as entrée into the community. Mentoring often begins around them. Building activities provide opportunities to quickly become absorbed into the culture of the laboratory. The processes of building artifact models also provide opportunities for the researcher to build integrated mental representations. For instance, in Lab A, building a physical construct to condition with the flow loop facilitates building a mental representation that selectively integrates concepts from cell biology and fluid dynamics-one that represents, for example, biological aspects of the endothelial cells with respect to mechanical forces in terms of the integrated concept of arterial shear rate (force of blood as it flows over these cells, causing elongation, proliferation, and so forth). Such interactive mental/physical representation building takes place over short periods of time during the hands-on processes and over longer spans. In Lab D, for instance, one researcher built a computational simulation and dynamic visualization of the dish model system and interacted with others working on the dish system itself. It was only over the course of more than a year of building and experimenting with both that the entire group of researchers was led to a new way of conceptualizing the propagation of "bursts", of electrical activity in the dish (Nersessian \& Chandrasekharan, 2009).

Importantly, the custom-built technologies of the biomedical engineering research laboratories are not stable artifacts. As parts of model systems they are designed and redesigned in the context of an experiment, and from one research project to another. Further, one device often leads to the creation of a new device. For instance, the flow loop studies led to the development of the construct model, which in turn led both to a redesign of the flow loop device and to the design of additional new simulation devices. In these circumstances the 
histories of the devices within the evolving research program of the laboratory become a vital resource for present-day research. In research, history is appropriated hands-on in the lore of the laboratory as meaningfully related to working with devices. It is important in moving the research forward for researchers to know, for instance, what, how, and why design changes have been made to a device. Thus, the current design is understood as conditioned on the problem situation as it existed for the laboratory at a prior time. So the historicity of the devices is a resource for novel design options.

With this basic understanding of the labs and their research practices in hand, we are now in a position to address the reflexive goal of this paper: drawing on the framework of distributed cognition to interpret problem-solving processes in the labs while using our findings and the issues they raise to further develop that framework.

\section{General discussion}

Proponents of the distributed cognition framework seek to reconceptualize cognitive processes as comprising systems of humans and artifacts. To date, distributed cognition researchers have focused much of their attention on the artifacts that participate in cognitive processes and on the roles of the humans in coordinating the generation, manipulation, and propagation of artifact representations as they accomplish cognitive work. Of course, as Hutchins and others have noted, brains are parts of cognitive systems and perceptual and motor processes play a role in coordinating artifact representations (Alac \& Hutchins, 2004; Becvar, Hollan, \& Hutchins, 2008). However, the nature of the representations within the bounds of the human components, which facilitate their participation in a cognitive system, have received scant attention. As will be demonstrated in Section 4.2, our data provide evidence that researcher representations are themselves model-like in structure-traditionally called "mental models." From the perspective of distributed cognition, researcher mental models and device model systems constitute distributed inferential systems through which candidate problem solutions are achieved. In what follows I use the notion of interlocking models to explicate dimensions of such distributed inferential systems.

Interlocking models is a system-level interpretation we developed to capture dimensions of research practices that cut across many of our coding categories (Kurz-Milcke, Nersessian, \& Newstetter, 2004; Nersessian, 2005; Nersessian et al., 2003). This multidimensional notion serves to articulate relations among the components of the laboratory cast as a cognitive-social-cultural system. In particular, it provides a means of specifying in what ways the simulation devices serve as hubs. As with transportation systems, where many service lines interlock at central stations, devices serve to interlock many dimensions of practice. Three dimensions pertinent to articulating distributed model-based reasoning will be considered in turn:

1. Interdisciplinary facets

2. Researcher and artifact system components 
3. Configurations of models in experiments.

\subsection{Interdisciplinary interlocking}

In this field, experimentation requires that researchers create models by interlocking conceptual, material, and methodological facets of biology and engineering. Researcher conceptual models are hybrid representations, as are artifact model systems. Fig. 6 provides partial schematic representations of areas that contribute such facets to the make-up of artifact and mental models.

Our data on how researchers conceptualize and understand their model systems provide numerous examples of interdisciplinary interlocking. Transcript material from several Lab A researchers illustrate this for the construct and flow loop model system. For a simulation to enable prediction about the in vivo phenomena, the flow loop and construct model system needs to behave as though blood were flowing through an artery to a satisfactory degree of approximation. The flow loop, as a model, represents the shear stresses during blood flow in an artery to a "1st order approximation of a blood vessel environment...as blood flows over the lumen", and enables a "way to impose a very well-defined shear stress across a very large population of cells." But a flow loop simulation is "something very abstract because there are many in vivo environments and many in vivo conditions within that environment. Things change constantly in our bodies over our lifetimes; including physiological flow rates." The researchers make this approximation in design because "as engineers, we try to eliminate as many extraneous variables as possible.... so our conclusions can be drawn from the change of only one variable.' The original flow loop was designed to flow cells, but "cell culture is not a physiological model' and though much still is learned by just using cells, "putting cells in plastic and exposing them to flow is not a very good simulation of what is actually happening in the body. Endothelial cells... have a natural neighbor called smooth muscle cells... these cell types communicate with one another."
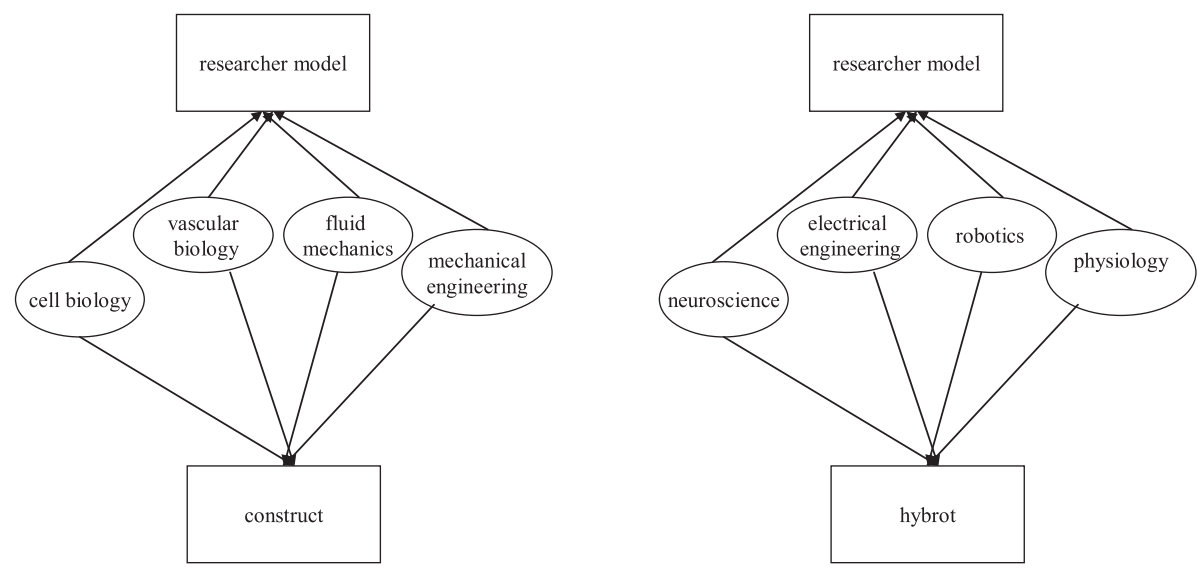

Fig. 6. Interlocking interdisciplinary models. 
To address this concern, biological and engineering materials and methods were employed to engineer the construct device. Unlike cell cultures on slides, constructs are three-dimensional surfaces in which cells are embedded. The construct model "behaves like a native artery because that's one step closer to being functional." The constraints of the flow loop (designed originally for cells on slides and modified slightly for the thicker constructs), however, require that the tubular constructs be cut open and flowed flat (unlike an in vivo artery). However, as the endothelial cells that line an artery in vivo are so small relative to the artery, the researchers believe that flowing the liquid (representing blood) over the flat in vitro construct (representing the artery) is a manipulation that will provide accurate enough information about the effect of forces on the endothelial cells. From the "cell's perspective... the cell [in vivo in an artery] sees basically a flat surface. The curvature is maybe over one centimeter, whereas the cell is like a micrometer... so to the cell it has no idea that there's actually a curve to it." So, other than in the case of an implantation experiment with an animal (often called "ex vivo" model), researchers believe there is no need to flow constructs in tubular form, which would require major changes to the flow loop. However, should it be found out, for instance, that in vivo "there's a whole different pattern of genes that are upregulated in pulsatile shear [in vitro]" then a new flow-loop-construct model system would need to be designed to simulate higher-order effects, such as that in vivo, "blood sloshes around in the blood vessel."

In just this brief exemplar of one model system, the interdisciplinary interlocking models comprise at least:

1. Biological and engineering models of in vivo phenomena in the wider community (as detailed, e.g., in texts and journals)

2. Bio-engineered in vitro artifact models

3. Researcher mental models of

- in vivo and in vitro phenomena

- devices qua in vitro models

- devices qua engineered models.

The next section examines how distributed cognitive processes comprise systems of interlocking researcher models and artifact models.

\subsection{Distributing cognition: "Putting a thought into the bench top",}

\subsubsection{Researcher models}

Our data on how researchers think about and reflect on the in vivo phenomena and the in vitro devices provide substantial evidence that the mental representations they use in problem solving and reasoning have a model-like structure (see, Fig. 2). That is, they are organized representations of the parts of physical systems and interactions among these, customarily referred to as "mental models." The data on how these researchers explain, predict, and otherwise reason support the interpretation that the long-term representations they 
draw upon consist of organized understandings comprising representations of the structures, functions, and/or behaviors of the phenomena they are investigating and of the artifact models they create for experimenting.

As noted in Section 2.4, model-based cognition is a central superordinate category deriving from our coding of transcripts. Combined, field observations and transcripts of interviews and research meetings provided ample evidence of the researchers constructing and simulating model-like representations of entities and processes for cognitive tasks. They reason, explain, and predict by means of model representations. So we have been seeking to understand how researcher mental models and artifact model systems function together as components of distributed cognitive processes. The mental models literature comprises a wide range of cognitive science research that posits models as organized units of mental representation that are used in various cognitive processes, including reasoning, problem solving, discourse comprehension, and sense making. As I have noted in previous writings (Nersessian, 2002, 2008a,b), there are two primary usages of the term in the literature: one addresses the nature of the long-term memory representations (see, e.g., Gentner \& Stevens, 1983); the other addresses the nature of the working memory representations in inferential processes, that is, the activity of "mental modeling" in discourse interpretation (see, e.g., Perrig \& Kintsch, 1985), logical reasoning (see, e.g., Johnson-Laird, 1983), and mental simulation (see, e.g., Nersessian, 1992b, 2008a). The hypothesis I advanced was that "in certain problem-solving tasks humans reason by constructing a mental model of the situation, events, and processes in working memory that in dynamic cases can be manipulated through simulation" (Nersessian, 2002; p. 143). ${ }^{6}$ This hypothesis derived from examining a range of historical records of scientific reasoning, the original conception of reasoning by means of mental simulation by Kenneth Craik (Craik, 1943), and extensive experimental literature over the last 25 years of research on mental modeling, mental animation, mental spatial simulation, and embodied mental representation. The full argument in support of this hypothesis is developed in Chapter 4 of Creating Scientific Concepts (Nersessian, 2008a). Recent psychological research, based on observational studies of scientists and engineers as they try to solve research problems, lends support to the hypothesis and further details the nature and role of mental model-or conceptualsimulations (Christensen \& Schunn, 2008; Trafton, Trickett, \& Mintz, 2005; Trickett \& Trafton, 2007).

Thus far I have been using the expression "mental models" to connect my account of scientific cognition with an extensive literature on mundane cognition. Before proceeding to extend that notion to distributed inferential processes, I now shift to the more neutral descriptor "researcher model." The traditional correlates "mind-body," "mental-physical," and "internal-external" (to the body) are laden with dualistic assumptions (Nersessian, 2005). Thus, for the remainder of my analysis I will use "researcher model", and "artifact model," where the former refers to model representations and processes inside the bounds of a human body and the latter, to other model components of the distributed cognitive system. The objective of the remainder of this paper is to extend the notion of simulative model-based reasoning to a distributed notion in which researcher and artifact representations are co-participants in inferential 
processes. The extension of the hypothesis is that in simulative model-based reasoning inferences arise through processing information in the system that comprises researcher(s) memory and artifact models. ${ }^{7}$

\subsubsection{Distributed model-based reasoning}

One researcher characterized what they do in experimenting by means of simulation models as "putting a thought into the bench top and seeing whether it works or not." We found this characterization quite apt. As an instantiated thought, the device is a physically realized representation with correspondences to the researcher model. As a tangible artifact, it evolves along with the researcher's understanding in experimental processes. As a representation, it refers both to the researcher model and to the in vivo phenomena. Simulations with artifact model systems are integral to the researcher models in that they are intended to function epistemically. That is, the artifact model is a site of simulation not just of some biological or mechanical process but also of the researcher's understanding. In the search for knowledge about in vivo systems, researcher and artifact models interlock both in concurrent simulation processes, in which building and simulation activities contribute directly to transformations of the researcher working memory model, and over the longer term, through processes that bring about changes in long-term memory representations.

An experiment with an artifact model provides an extension of the scientific practice of thought experimenting (the "science fiction", remarked on in Fig. 5B)-more complete and complex and potentially less subject to individual bias and error. It affords a more detailed representation, a wider range of manipulations, and more control than is possible for a thought experiment. In a manner similar to how microscopes and telescopes extend scientists' capacity to see, artifact simulation models extend their biological capacity to perform simulative reasoning. As with thought experimenting, the model system simulation contributes to predictions about how the in vivo system might perform under specified conditions. Whether one is warranted in transferring these to in vivo phenomena depends on the kinds of considerations discussed briefly in Section 4.1, which concern the fit between the representations and manipulations performed and the in vivo phenomena. For instance: Is a first order approximation sufficient for representing blood flow? Do the effects of shear stress on the cells in a flat construct differ in relevant ways from the effects on tubular arteries? And so forth. Simulations with models, then, provide a kind of counterfactual reasoning. As another researcher explained: "We typically use models to predict what is going to happen in a system [in vivo]. Like people use mathematical models to predict.... what's going to happen in a mechanical system? Well, this is an experimental model that predicts what would happen —or you hope that it would predict—what would happen in real life.'

The argument being made here is that the "experimental model that predicts" is the interlocked, distributed model system comprising researcher and artifact. Reasoning by means of this system involves co-processing information in human memory and in the environment. That is, as cast within the distributed cognition framework, the problem solver does not simply use artifact representations; rather, they are incorporated directly into cognitive processing. The nature of the mechanisms connecting human and artifact components is 
still an open question for cognitive science. Research needs to address both cases of concurrent, interactive manipulations of researcher and artifact models and cases where simulation is carried out by the artifact model, and its results lead to changes in researcher long-term models. ${ }^{8}$

The analysis in this section provides an argument extending the notion of model-based cognition to comprise interlocking researcher and artifact models for distributing cognitive processes across such systems. In these labs, problem-solving processes comprise experiments that generate, manipulate, and propagate these interlocked models. Simulative model-based reasoning is a process of co-constructing and manipulating the researcher models of the phenomena and of the device and the model that is the device, each incomplete. In experimental processes, interlocking researcher and artifact models form distributed experimental configurations from which inferences flow. I illustrate this understanding of experimentation by means of an extended example from Lab A that provides a snapshot of a problem-solving process that extended over several years and was carried out by means of an evolving distributed inferential system.

\subsection{Distributed experimental configurations: The vascular construct model system}

In experimental situations, models tend to be put into interlocking configurations, that is, they are not isolated entities, but stand in particular relations to other models-researcher and artifact. Analyzing the design and execution of an experiment will provide a means of articulating this dimension of interlocking models. Soon after A7 arrived at Lab A she was designated the "person who would take the construct in vivo," meaning that her research was directed towards conducting experiments with an animal that serves as a model for the human body in the context of the experiment. This objective immediately required that she would (a) need to design and build a construct that would both more closely mimic the functional characteristics of an in vivo artery than was used in most other experiments and would have sufficient strength to withstand the force of in vivo blood flow; (b) modify the flow loop so that it would work with tubular constructs in tubular form; and (c) arrange for an animal (baboon) to be surgically altered so as to experiment with the construct outside of its body and in a minimally invasive way. It also required that she bring together the strands of research being conducted by nearly all the other lab members. As she expressed it, "to go to an in vivo model we have to have all, well most of the aspects that people have studied." She proceeded to identify components stemming from other researchers, stressing "so this is integration of what they've learned....you can't just study one aspect." "To improve mechanical integrity....is gonna obviously integrate the results of colleagues here in the lab.' A7's integrative position in the lab problem space is further evidenced in the drawing made by the director (Fig. 5A).

When we started, she had been in the laboratory about a year but was still in the process of defining the specific goals and problems of her research. Our analysis is based on field observations of her conducting the parts of her research that took place in the laboratory (the baboon lived in a laboratory in another state); interviewing her as it progressed, with a final postgraduation interview; video and audio transcripts of the lab meetings in which she 
presented; and several of her writings. Her final overarching definition of the problem was to determine whether it would be possible to use circulating endothelial cells ("progenitor cells"') derived from a patient's peripheral blood to line the vascular graft. The endothelial cells that line the artery are among the most immune-sensitive cells in the body. If the patient's own endothelial progenitor cells could be harvested and used, that would greatly enhance the potential of a vascular graft. However, the progenitor cells do not modulate thrombosis, which is a function of the mature cells. A7 hypothesized that shear stress conditioning (by means of the flow loop) the construct prior to implantation would solve the problem of platelet formation and the resulting thrombosis. Before turning to our analysis of her problem solving as an example of a distributed model-based cognition, it is instructive to examine her own succinct summary statement.

What is most notable from A7's account of her experiment is she seamlessly interlocks in thought and expression biological and engineering concepts and models as she had enacted these in building and assembling the components of her model systems and conducting and drawing inferences through experiments:

We used the shunt to evaluate platelet deposition and that would be-in other wordswere the cells, as a function of the treatment that they were given before they were seeded onto the engineered tissue, able to prevent blood clotting? And so we specifically measured the number of platelets that would sit down on the surface. More platelets equals a clot. So, it ended up being that we were able to look at the effects of shear stress preconditioning on the cells ability to prevent platelets and found that it was actually necessary to shear precondition these blood derived cells at an arterial shear rate, which I used 15 dynes per square centimeter compared to a low shear rate, which in my case I used like 1 dyne per square centimeter, so, a pretty big difference. But I found that the arterial shear was necessary to enhance their expression of anti-coagulant proteins and therefore prevent clotting. So in other words, the shear that they were exposed to before going into the shunt was critical in terms of magnitude, for sure.

The italicized terms mark reference both to interlocking interdisciplinary models as they function in her understanding and reasoning and to interlocked physical simulation models. To unpack a few of her expressions "the cells" are the endothelial progenitor cells she extracted from baboon blood and seeded onto the "engineered tissue" (vascular construct device). The "treatment" they received was "shear stress preconditioning" conducted by using the modified flow loop device. The objective of her research was to determine if, and at what level, the preconditioning ("arterial shear" simulation) of constructs would "enhance their [cells] expression of anti-coagulant proteins" ("prevent platelets"). She found, through several iterations of the entire ex vivo model system ("used the shunt to evaluate platelet deposition"), that the in vivo human arterial shear rate (" 15 dynes/cm",") was required for sufficient protein expression ("was critical in terms of magnitude"). Likewise, her instantiated 'thought'" about the treatment of the cells led to a revision of her conceptual understanding of the vascular construct so as to reflect the necessity of using arterial shear in order to prevent thrombosis. 


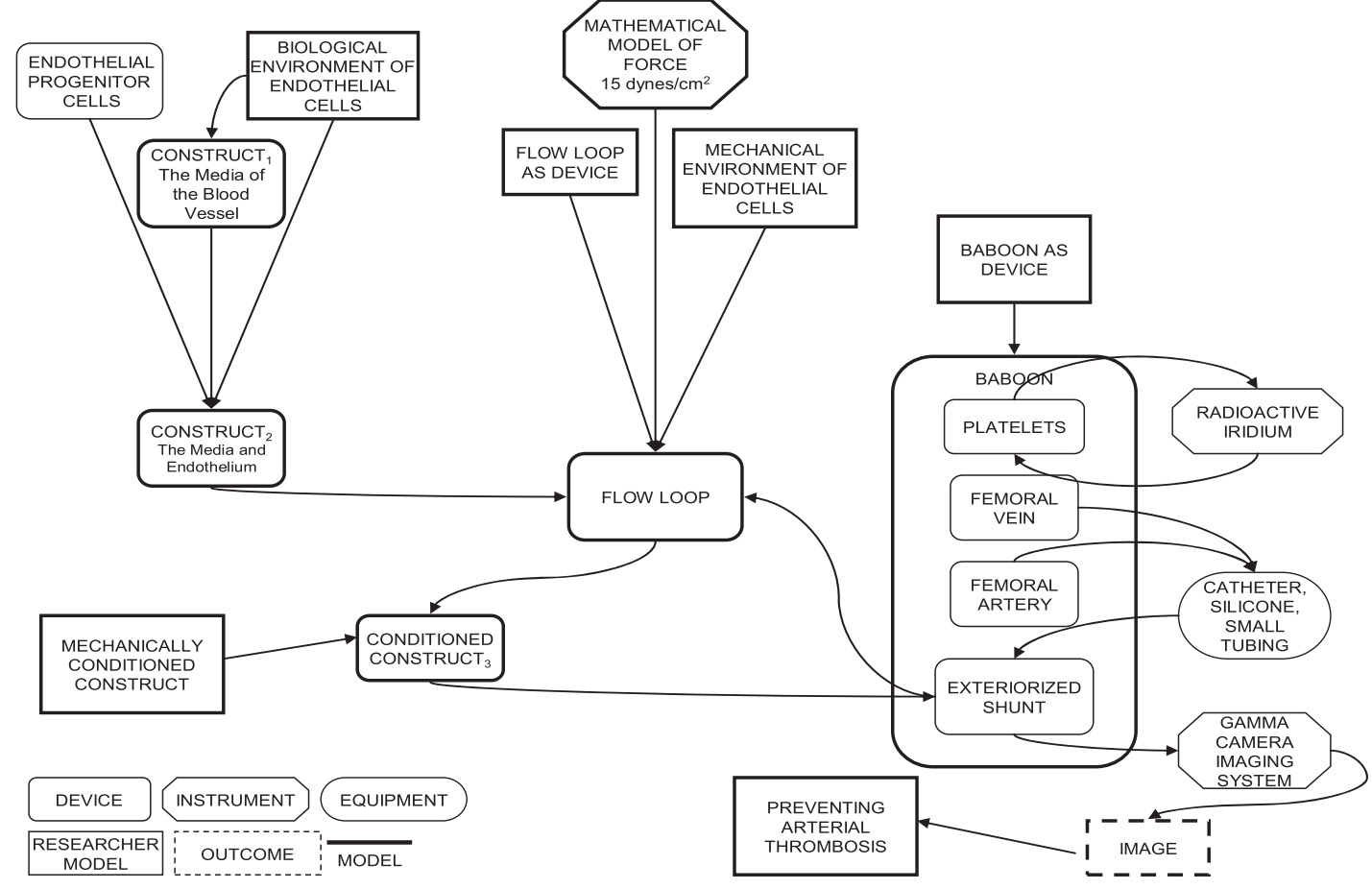

Fig. 7. Distributed vascular construct model system (partial).

The diagram in Fig. 7 provides a pared-down representation of our analysis of the vascular construct model system for this experiment. It was drawn from our data quite a while before this final interview, but each component appears in her explanation. On our interpretation, it traces the construction, manipulation, and propagation of researcher and artifact models within the distributed problem-solving system that constitutes the experiment. In the figure, the models are highlighted by thick lines. The flow arrows represent the propagation of representations in the system as they are generated and manipulated.

To keep the diagram from becoming too complex, the numerous connections to other researchers in the lab problem space (mapped in Fig. 5A) are not included, but the construct, flow loop, and baboon models are to be understood as communal achievements, representing years of research. Each researcher model is a part individual, part community representation. The device models represent and perform as aspects of a cardiovascular system: The construct models represent and perform as selected aspects of the biological environment of a blood vessel, the flow loop model represents and performs as shear stresses on arterial walls, and the baboon model represents and performs as blood flow through a human artery. Neither artifact nor researcher models in this experimental set up are static; rather, they are representations that changed over time as each component was developed. There are three major components of this model system that I will call "construct', (left third of diagram), "flow loop" (middle), and "baboon", (right third). It required over 3 years of designing, building, and experimenting with first two components before A7 could conduct the final 
ex vivo experiments over a further 2-year period. Model system configurations, though continually evolving artifacts, are long-term investments. It is not possible here to provide a detailed account of the numerous cycles of designing, building, simulating, and evaluating the models represented in each part of the diagram. I provide a brief outline.

Considerable novel research went into just the making of the construct (diagram left third) so that it could be used ex vivo. Issues of mechanical integrity (strength) became significant as it needed to be able to withstand nearly normal blood forces and also not leak. The desired final experimental configuration required that this construct model be what they considered the most "physiologic"' one the lab has created in that it instantiated all but the outer layer (adventitia), which the researcher thought was not necessary to the experiment and might even grow on its own. Endothelial progenitor cells (EPCs) were extracted from a baboon's peripheral blood. When working just with the EPCs, she used the lab flow loop model at various shear rates and then used several instruments to extract information about their protein and gene expression. Numerous iterations of manipulating EPCs and using various instruments, such as the flow cytometer to examine the cells for expression of molecules for thrombomodulin, facilitated her building a researcher model of their function and behavior in relation to shear stresses, and contributed to building the final construct device for these experiments. Constructing this artifact model further required isolating an intact elastin scaffold, removing vascular smooth muscle cells from carotid arteries of baboon (sacrificed for experiments other than her own), and determining the right collagen mix and the scaffold material for suturing (Teflon).

For conditioning the constructs in tubular shape (diagram middle third), A7 had originally proposed redesigning the chamber of the flow loop to better approximate the in vivo model. In the end, significant redesign turned out to be unnecessary because she had the insight that it should be possible to design an external shunt for the flow loop-making an analogy directly with the shunt she had designed earlier for the animal model — and attach the construct to that for simulating a range of shear stresses. The animal model (diagram right third) was needed to provide a functional evaluation of the EPCs in an environment more closely approximating the in vivo environment than an artifact model. The animal model comprises a baboon, surgically altered so that an exteriorized shunt connects the femoral vein and the femoral artery, allowing a small amount of blood flow to be diverted through a construct during an experiment. In setting up the experiment a much longer tube is attached to the shut so that the construct can be placed directly on the gamma camera (a commercially available instrument the size of a small table) to capture and observe platelet formation during real-time blood flow. The baboon sits in a specially designed restraining chair and has a suit over its body to prevent it from pulling on the shunt. The baboon's blood is injected with iridium so that platelets will be made visible through the gamma camera. The construct is then disconnected from the baboon and other instruments and software programs are used to analyze the EPCs for information about expression of thrombomodulin, optical density, and electrical resistance.

Although the animal model provides a better physiological representation of in vivo human phenomena, it is less reliable than a fully in vitro engineered system because "in the lab we can control their [endothelial cells] environment completely....we can control exactly what flow is like and we can monitor by visually seeing it. But when we move to an animal model 
it's more physiologic - the challenge then is that it's a much more complex system.' To advance the research, some control and precision needed to be sacrificed so as to better exemplify complex characteristics of human physiology. A7 made several trips over 2 years to the out-of-state lab where the animal models reside to run experiments, modify her simulations, and, in the end, she was able to prevent platelet formation. On a distributed cognition interpretation, the "experimental model that predicts" comprises the entire system of researcherartifact-animal models through which the inference was made that if human EPCs were to be conditioned at the normal arterial sheer rate prior to vascular graft implantation, they would function as mature endothelial cells with respect to modulating thrombosis.

\section{Conclusion}

Our use of distributed cognition as a framework for interpreting the research practices of these laboratories helps to make sense of how engineering scientists think by means of the artifact models they design and build. In negotiating the in vivo-in vitro divide, they are in a real sense practicing what the researcher in Lab D called "science fiction" (Fig. 5B). They translate their understandings of the phenomena under investigation into real-world simulation models and revise their understandings through simulation. To fathom how engineering scientists think by means of artifact models requires attending to the nature of the researcher representations that participate in problem-solving processes. Here I have argued that they, too, are model-like representations, and that inferential processes comprise an interlocking system of researcher and artifact models.

Adding to this account an appreciation of the devices as "hubs" for interlocking the various dimensions of practice, we move further along the path toward an integrative understanding of cognitive-social-cultural dimensions of research practices. As hubs, devices are focal points around with lab activities revolve and through which they interlock. Devices and model systems are what socio-cultural studies of science refer to as the "material culture", of the community, but are also what cognitive studies of science refer to as "cognitive artifacts" participating in the representational, reasoning, and problemsolving processes of a distributed system. Our data lead to their interpretation as cognitivecultural artifacts. They are representations and thus play a role in model-based reasoning and problem solving; they are central artifacts around which social practices form; they are sites of learning; they connect one generation of researchers to another; they perform as cultural ratchets (Tomasello, 1999) in an epistemic community (Knorr Cetina, 1999), enabling researchers to build upon the results of the previous generations, and thus move the problem solving forward.

\section{Notes}

1. In addition, for 2 further years, we conducted a study of a bio-robotics laboratory with the objective of testing the robustness of our findings about learning and principles for 
designing effective learning environments derived from Labs A and D through seeing whether there was transfer to an out-of-domain research laboratory. Since the primary focus of that study was a comparison of learning practices, data from it are not included in the analysis presented here.

2. I place the word "theory" in quotation marks here because what grounded theory advocates mean by that term better approximates what Tweney has called a "framework,' as discussed previously.

3. If we add "'analogy," which is a type of model that we coded for separately, the total rises to 723 .

4. What it means to parallel in these models is captured by the notion of "exemplification" as formulated by Nelson Goodman (1968) and Catherine Elgin (1996). As introduced by Goodman, a representation exemplifies certain features if it "both is and refers to" something which has those features; that is, "[e]xemplification is possession plus reference" (Goodman, 1968, 53). Devices both possess and refer to the selected features of the in vivo systems, such as the force with which the blood flows in a human artery.

5. Our notion of cognitive partnering might appear similar to "actor network" theory introduced by Bruno Latour (1987). Salient differences, though, are as follows: first, on our account not all "'actors"' are equal, that is, there would be no distributed cognitive system without the human agents, and second, "agency" as we understand it implies "intentionality," so the artifacts can perform cognitive functions in the system and exhibit independent behaviors, but are not, themselves, agents. The point we are making is that learning and research require researchers to form relationships, and one that we witness is forming a relationship with the devices, which involves researchers attributing agency to these artifacts, living and nonliving.

6. Significant cognitive science research supports the hypothesis that simulation is a fundamental form of computation in the human brain (see Barsalou, 2008 for an overview).

7. For related views, see Gorman (1997); Gorman \& Carlson (1990); and Greeno (1989).

8. Trafton et al.'s (2005) finding that in the presence of computer visualizations scientists do considerable mental manipulation in interaction with the visualization provides an example of the former case. Christensen and Schunn's (2008) research on conceptual simulation and prototyping in engineering design showed that conceptual simulation decreased when prototypes were constructed, providing an example of the latter case.

\section{Acknowledgments}

I gratefully acknowledge the support of the National Science Foundation ROLE grants REC0106773 and DRL0411825 in conducting the research on the laboratories. This analysis derives from research conducted with my co-PI, Wendy Newstetter, and with our research group, especially Ellie Harmon, Elke Kurz-Milcke, Lisa Osbeck, Christopher Patton, and 
Sanjay Chandrasekharan. I thank the members of the research labs for allowing us into their work environment, letting us observe them, and granting us numerous interviews. I thank also Ryan Tweney, Michael Gorman, and the three anonymous referees for their comments on the earlier version of this article.

\section{References}

Alac, M., \& Hutchins, E. (2004). I see what you are saying: Action as cognition in fMRI brain mapping practice. Journal of Cognition and Culture, 4(3-4), 629-662.

Barsalou, L. (2008). Grounded cognition. Annual Review of Psychology, 59, 615-645.

Becvar, A., Hollan, J., \& Hutchins, E. (2008). Representing gestures as cognitive artifacts. In M. S. Ackerman, C. Halverson, T. Erickson \& W. A. Kellog (Eds.), Resources, co-evolution, and artifacts: Theory in CSCW (pp. 117-143). NewYork: Springer.

Christensen, B. T., \& Schunn, C. D. (2008). The role and impact of mental simulation in design. Applied Cognitive Psychology, 22, 1-18.

Craik, K. (1943). The nature of explanation. Cambridge, England: Cambridge University Press.

Dunbar, K. (1995). How scientists really reason: Scientific reasoning in real-world laboratories. In R. J. Sternberg \& J. E. Davidson (Eds.), The nature of insight (pp. 365-395). Cambridge, MA: MIT Press.

Dunbar, K., \& Blanchette, I. (2001). The in vivo/in vitro approach to cognition: The case of analogy. TRENDS in Cognitive Science, 5, 334-339.

Eisner, E. (2003). On the art and science of qualitative research in psychology. In P. Camic, J. Rhodes, \& L. Yardly (Eds.), Qualitative research in psychology. Washington, DC: American Psychological Association.

Elgin, C. Z. (1996). Considered judgment. Princeton, NJ: Princeton University Press.

Gentner, D., \& Stevens, A. L. (1983). Mental models. Hillsdale, NJ: Erlbaum.

Giere, R. N. (1988). Explaining science: A cognitive approach. Chicago: University of Chicago Press.

Glaser, B., \& Strauss, A. (1967). The discovery of grounded theory: Strategies for qualitative research. Piscataway, NJ: Aldine Transaction.

Goodman, N. (1968). Languages of art. Indianapolis, IN: Hackett.

Goodwin, C. (1995). Seeing in depth. Social Studies of Science, 25, 237-274.

Gorman, M. (1997). Mind in the world: Cognition and practice in the invention of the telephone. Social Studies of Science, 27, 583-624.

Gorman, M. E., \& Carlson, W. B. (1990). Interpreting invention as a cognitive process: The case of Alexander Graham Bell, Thomas Edison, and the telephone. Science, Technology, and Human Values, 15, 131-164.

Greeno, J. G. (1989). Situations, mental models, and generative knowledge. In D. Klahr \& K. Kotovsky (Eds.), Complex information processing (pp. 285-318). Hillsdale, NJ: Erlbaum.

Hall, R., Stevens, R., \& Torralba, T. (2002). Disrupting representational infrastructure in conversation across disciplines. Mind, Culture, and Activity, 9, 179-210.

Hollan, J., Hutchins, E., \& Kirsch, D. (2000). Distributed cognition: Toward a new foundation for humancomputer interaction research. ACM Transactions on Computer-Human Interaction, 7(2), 174-196.

Hutchins, E. (1995). Cognition in the wild. Cambridge, MA: MIT Press.

Johnson-Laird, P. N. (1983). Mental models. Cambridge, MA: MIT Press.

Knorr Cetina, K. (1999). Epistemic cultures: How the sciences make knowledge. Cambridge, MA: Harvard University Press.

Kurz-Milcke, E., Nersessian, N. J., \& Newstetter, W. (2004). What has history to do with cognition? Interactive methods for studying research laboratories Journal of Cognition and Culture, 4, 663-700.

Latour, B. (1987). Science in action. Cambridge, MA: Harvard University Press.

Lave, J. (1988). Cognition in practice: Mind, mathematics, and culture in everyday life. New York: Cambridge University Press. 
Lincoln, Y., \& Guba, E. (1985). Naturalistic inquiry. Newbury Park, CA: Sage.

Morgan M. S., \& Morrison M. (Eds.) (1999). Models as mediators. Cambridge, England: Cambridge University Press.

Nersessian, N. J. (1992a). How do scientists think? Capturing the dynamics of conceptual change in science. In R. Giere (Ed.), Minnesota studies in the philosophy of science (pp. 3-45). Minneapolis, MN: University of Minnesota Press.

Nersessian, N. J. (1992b). In the theoretician's laboratory: Thought experimenting as mental modeling. In D. Hull, M. Forbes, \& K. Okruhlik (Eds.), PSA 1992, Vol. 2 (pp. 291-301). Lansing, MI: PSA.

Nersessian, N. J. (1995). Opening the black box: Cognitive science and the history of science. Osiris, 10, 194211.

Nersessian, N. J. (2002). The cognitive basis of model-based reasoning in science. In P. Carruthers, S. Stich, \& M. Siegal (Eds.), The cognitive basis of science (pp. 133-153). Cambridge, England: Cambridge University Press.

Nersessian, N. J. (2005). Interpreting scientific and engineering practices: Integrating the cognitive, social, and cultural dimensions. In M. Gorman, R. D. Tweney, D. Gooding, \& A. Kincannon (Eds.), Scientific and technological thinking (pp. 17-56). Hillsdale, NJ: Erlbaum.

Nersessian, N. J. (2006). The cognitive—cultural systems of the research laboratory. Organization Studies, 27, $125-145$.

Nersessian, N. J. (2008a). Creating scientific concepts. Cambridge, MA: MIT Press.

Nersessian, N. J. (2008b). Mental modeling in conceptual change. In S. Vosniadou (Ed.), Interntional handbook of conceptual change (pp. 391-416). New York: Routledge.

Nersessian, N. J., \& Chandrasekharan, S. (2009). Hybrid analogies in conceptual innovation in science. Cognitive Systems Research, 10, 178-188.

Nersessian, N. J., Kurz-Milcke, E., Newstetter, W., \& Davies, J. (2003). Research laboratories as evolving distributed cognitive systems. In D. Alterman \& D. Kirsch (Eds.), Proceedings of the cognitive science society 25 (pp. 857-862). Hillsdale, NJ: Erlbaum.

Osbeck, L., \& Nersessian, N. J. (2006). The distribution of representation. The Journal for the Theory of Social Behaviour, 36, 141-160.

Perrig, W., \& Kintsch, W. (1985). Propositional and situational representations of text. Journal of Memory and Language, 24, 503-518.

Strauss, A., \& Corbin, J. (1998). Basics of qualitative research: Techniques and procedures for developing grounded theory (2nd ed.). Thousand Oaks, CA: Sage Publications.

Tomasello, M. (1999). The cultural origins of human cognition. Cambridge, MA: Harvard University Press.

Trafton, J. G., Trickett, S. B., \& Mintz, F. E. (2005). Connecting internal and external representations: Spatial transformations of scientific visualizations. Foundations of Science, 10, 89-106.

Trickett, S. B., Fu, W. T., Schunn, C. D., \& Trafton, J. G. (2000). From dipsy-doodles to streaming motions: Changes in representation in the analysis of visual scientific data. Paper presented at the Proceedings of the Cognitive Science Society 22.

Trickett, S. B., \& Trafton, J. G. (2007). "What if....': The use of conceptual simulations in scientific reasoning. Cognitive Science, 31, 843-876.

Tweney, R. D. (1989). A framework for the cognitive psychology of science. In B. Gholson, W. R. Shadish Jr, R. A. Neimeyer, \& A. C. Houts (Eds.), Psychology of science: Contributions to metascience (pp. 342-366). New York: Cambridge University Press. 